\title{
ASJA VERDE: INTERVENÇÃO PARTICIPATIVA DE EDUCAÇÃO AMBIENTAL NA ASJA - ASSOCIAÇÃO DOS SURDOS DE JAÚ E REGIÃO
}

Tabita Teixeira ${ }^{1}$

Adauto Caramano ${ }^{2}$

Resumo: O projeto ASJA VERDE trata de uma intervenção participativa de Educação Ambiental realizado em 2015 em conjunto com o Instituto Pró-Terra e a Associação dos Surdos de Jaú e Região (ASJA), ambos do Município de Jaú/SP. Os objetivos deste projeto foram promover a sensibilização e conscientização socioambiental dos participantes surdos, trabalhar com a subjetividade da pessoa surda regional e criar ações para a promoção da sustentabilidade da ASJA, através de 14 encontros em três oficinas principais: Meio Ambiente, Cultura e de Sustentabilidade. Para a sua realização, foram utilizadas técnicas participativas e a Língua Brasileira de Sinais como meio de comunicação. Ao final foi construído o "Plano de Sustentabilidade da ASJA".

Palavras-chave: Educação Ambiental; Surdos; Libras; Sustentabilidade. 


\section{Introdução}

A degradação tanto do meio ambiente quanto do ser humano são os resultados de uma relação fragmentada da nossa sociedade, onde os problemas socioambientais como: poluição, falta de água e saneamento básico, ocupação desordenada, desmatamento, preconceitos, corrupção, fome, pobreza entre outros tornaram-se a atual realidade. Desta forma, muitos se esqueceram ou nunca souberam o quanto toda a vida do planeta está conectada e interagindo entre si para manter o equilíbrio e a sua qualidade. Para atingir esse nível de consciência, a ética ambiental possui como princípio norteador as condutas, onde cada um desenvolve tal consciência ética quanto ao respeito dos ciclos de vida e os limites da exploração dos recursos naturais (PELICIONI; PHILIPPI JÚNIOR; 2002). Para Borges (2011), esta visão integrada do mundo em conjunto com a temática ambiental nas políticas públicas ajuda na adoção de posturas individuais e coletivas para a construção de uma sociedade mais justa, igualitária e sustentável.

Dessa forma, a Educação Ambiental se torna uma ferramenta poderosa na forma de difundir informações, conscientizar e sensibilizar a população quanto às questões socioambientais, principalmente na participação comunitária das pessoas para atingir a sustentabilidade (SORRENTINO et al., 2005). Para a sua promoção, cabe ao Poder Público garantir meios e ferramentas através das políticas públicas que possibilitem a preservação do meio ambiente, a qual é referida no Art. 225 da Constituição Federal (BRASIL, 2011). Uma que podemos citar seria a Política Nacional de Educação Ambiental, Lei Federal no 9.795/1999 (BRASIL, 2008), a qual define em seu Art. $1^{\circ}$ que a Educação Ambiental são os processos por meio dos quais tanto 0 indivíduo quanto o coletivo, constroem valores sociais, conhecimentos, habilidades, atitudes e competências voltadas para a conservação do meio ambiente e da cidadania, bem de uso comum do povo, essencial à sadia qualidade de vida e sua sustentabilidade. Nessa mesma lei, Art. 2oㅡ, a Educação Ambiental também é essencial e permanente, devendo estar em todos os processos educacionais, tanto formal quanto não formal.

Este projeto visou justamente por meio da Educação Ambiental não formal despertar a percepção socioambiental do sujeito usuário da Língua Brasileira de Sinais (Libras), o surdo. Estes viveram durante muito tempo marginalizados pela sociedade ouvinte ao longo de sua história tanto no Brasil quanto no mundo, passando por diversas barreiras sócio-políticas e culturais, além de preconceitos e a exclusão perante a sociedade ouvinte. Em sua trajetória, foram considerados doentes castigados pelo poder divino e sem importância pela sociedade desde a Grécia antiga até a Idade média; a desigualdade social como o acesso aos mesmos direitos e deveres dos ouvintes, a proibição de expressar a sua cultura e a sua própria língua, obrigação em moldar-se a vida dos ouvintes e a exclusão perante a sociedade oralista são alguns dos fatores que mobilizaram a comunidade surda até nos dias de hoje (MARTINO, 2011; PINTO; REZENDE JÚNIOR, 2007; STUMPF, 2008).

Revbea, São Paulo, V. 12, № 4: 219-239, 2017. 
De acordo com o IBGE (2010), o Brasil possui aproximadamente 9,7 milhões de brasileiros com algum grau de surdez, representando $5,1 \%$ da população. Deste total, 2 milhões possuem perda severa $(1,7$ milhões têm grande dificuldade de ouvir e 344,2 mil são totalmente surdos) e 7,5 milhões apresentam alguma dificuldade auditiva. A tendência é a população de surdos crescerem devido ao avanço da idade e estarem mais sujeitas a ruídos urbanos. De acordo com o aplicativo da Secretaria dos Direitos da Pessoa com Deficiência do Estado de São Paulo (2015 apud IBGE, 2010), o Município de Jaú/SP possui 5.732 deficientes auditivos, sendo nem todos estes surdos profundos.

Para a área da saúde, os surdos são pessoas que possuem certos graus de surdez - perda parcial ou total da audição -, passando desde leves (entre 20 e $40 \mathrm{~dB}$ ), moderados (40 e $70 \mathrm{~dB}$ ), severos (70 e $90 \mathrm{~dB}$ ) e profundos (mais de $90 \mathrm{~dB}$ ). $O$ termo surdez remete a aqueles que nascem totalmente surdos, já o termo deficiente auditivo é empregado quando um indivíduo adquire um déficit da audição durante alguma fase de sua vida, por meio de lesões, doenças como a meningite bacteriana ou virótica, infecções e exposições a ruídos (STRÖBEL, 2007; INES, 2014). O termo surdo trata da sua identidade, 0 orgulho em ser um sujeito que percebe, sente e representa 0 mundo ao seu redor de outra forma, o qual é mais sensível ao sentido da visão. É a forma que este grupo optou politicamente devido principalmente ao trabalho coletivo realizado em suas lutas sociais (MIORANDO, 2006) e foi o termo empregado durante a realização de todo este trabalho.

Ao se pesquisar e analisar o que há disponível sobre a Educação Ambiental voltada aos surdos nota-se que a maioria do que é publicado é voltada para a educação de crianças e jovens em escolas, as pesquisas ainda são incipientes quanto à adultos e a terceira idade nas comunidades surdas e em associações de surdos. Nestes locais, os surdos se comunicam e os mais velhos repassam aos mais novos informações, discutem assuntos, problematizam a relação do sujeito surdo com a sociedade, entre outros, por meio de ambientes que propiciem o aprendizado em contextos formais, como no caso de cursos ou palestras, e informais, como eventos sociais, campeonatos esportivos, etc., preservando sempre a herança da língua de sinais (MASSUTTI; QUADROS, 2007). As associações estão espalhadas pelo mundo inteiro, inclusive no Brasil, contando com mais de 140 associações em 22 estados, incluindo o Distrito Federal (CBS, 2015), e são importantíssimas também para a mediação dos sujeitos surdos, resgatando o seu pertencimento, valores, atitudes, costumes e tradições.

Mediante essa demanda de criação de um espaço em que a Educação Ambiental pudesse circular e que, de forma global, fosse assertiva às necessidades e condições das pessoas surdas por meio do uso de sua língua, a Libras, como língua de instrução dos conteúdos, pensou-se na criação de um projeto que abarcasse a complexidade pedagógica de envolvimento do público surdo. Desta forma o projeto, denominado. Desta forma, o projeto ASJA VERDE baseou-se numa intervenção participativa de Educação Ambiental na

revista brasileira educação ambiental 
Associação dos Surdos de Jaú e Região (ASJA), localizada no Município de Jaú/SP. Essa associação foi escolhida devido a seu importante papel, exercido desde 1997 após sua fundação, há 20 anos, frente à comunidade surda da cidade e das demais regiões e propiciar espaço para o diálogo com seus associados, os quais possuíam interesse em conhecer mais sobre as temáticas socioambientais do cotidiano e como tornar a ASJA mais sustentável e participativa. Tal trabalho procurou desenvolver nos participantes surdos: a percepção ambiental (PALMA, 2005) - por meio da sensibilização e conscientização -, o senso crítico quanto às questões socioambientais, 0 resgate do pertencimento (SÁ, 2005) da sua cultura e o fortalecimento e a sustentabilidade da Associação e de seus integrantes. Todo esse processo visou justamente a elaboração de um Plano de Ações sustentáveis para a ASJA.

\section{Metodologia}

Para este trabalho, foram estudadas as melhores formas da pedagogia, considerando a singularidade lingüística dos participantes e sua subjetividade desenvolvida através de experiências visuais, de atingir os objetivos esperados. O surdo possui como língua constitutiva (LODI, 2013) o sistema sensorial e motor, utilizando a anatomia visual emitida através dos sinais. A Libras - reconhecida pela Lei Federal no 10.436/2002 (BRASIL, 2002) - é uma língua de modalidade visual-espacial completa, ou seja, ela é estabelecida da visão e da utilização do espaço com movimentos das mãos, braços e o corpo, em conjunto com as expressões faciais, conforme apontado a partir das pesquisas de Stokoe (1978) na década de 60. Para Pereira (2013), a visão e a prática baseada nas vivências para o sujeito surdo sentir o mundo ao seu redor podem ser as técnicas mais eficazes na formação do conhecimento sobre determinado tema, que neste caso trata do meio ambiente e da sustentabilidade. Estas vivências em conjunto com a Libras permitem com que os surdos desenvolvam suas habilidades e as percepções ambientais.

Desta forma, foram empregadas metodologias e técnicas participativas, as quais permitiram o envolvimento do público alvo desde a construção até o desenvolvimento do projeto. De acordo com o CEPAM (2001), atualmente o mais interessante em trabalhar com a participação de comunidades seriam as metodologias que identifiquem a realidade e os desejos destas para que possam concretizar melhor as ações pré-planejadas, estimulando a percepção ambiental de cada um. Para Palma (2005), esta percepção é a interação de um indivíduo com o seu meio, através dos seus órgãos sensoriais e de seu interesse pelo objeto, baseado pelos seus conhecimentos, cultura e ética. Por isso cada pessoa possui percepções e significados diferentes sobre o mesmo objeto e também em momentos distintos. Com os surdos ocorre da mesma forma, pois tais sujeitos possuem cultura e conhecimento adquiridos ao longo da vida, logo, sua percepção da realidade é totalmente válida para poderem compreender o mundo em suas diversas formas e avaliar os espaços ambientais. Por isso, tal instrumento de Educação Ambiental permite a Revbea, São Paulo, V. 12, № 4: 219-239, 2017. 
construção da relação do ser humano com o ambiente para que se tornem mais participativos quantos as questões socioambientais (PALMA, 2005; HÖHER; PERES, 2012).

Para Campello (2007), a Pedagogia visual utiliza como ferramenta chave a visão para a experiência visual e experimental dos participantes. Desta forma, podemos utilizar recursos visuais para trabalhos pedagógicos também com os surdos, contribuindo assim para o desenvolvimento de sua linguagem. A cultura é inserida por meio de seus olhares com o auxílio de recursos visuais e didáticos, sendo assim, as características viso espaciais da Libras encontra uma forte aliada no campo das imagens para os métodos de aquisição do conhecimento e práticas sociais (ALBRES, 2013; FORTE; SILVA, 2010).

Sendo assim, toda a comunicação com os participantes foi realizada por meio da Libras, em que o educador ambiental usa a língua do aluno para explicar os conteúdos, utilizando técnicas que explorassem o seu campo visual-espacial e promovesse a sua participação como: Mapas mentais (OLIVEIRA, 2006), oficinas, dinâmicas, pesquisas, rodas de diálogos, palestras em Libras, desenhos, fotografias, saídas de campo a espaços naturais e culturais, filmagens e apresentação de vídeos. Durante os encontros, também foram utilizadas apresentações de slides para que os participantes pudessem acompanhar o raciocínio dos temas debatidos, utilizando imagens e animações como recursos visuais e uso estratégico de terminologias em língua portuguesa na modalidade escrita. O registro dos dados coletados foi através das fotografias, das atividades promovidas pelos participantes e pelas observações e anotações em um diário de campo.

A divulgação do projeto contou com a colaboração da ASJA, do Instituto Pró-Terra e dos próprios participantes, por meio dos sites institucionais (INSTITUTO PRÓ-TERRA, 2015; ASJA, 2015), das aulas de ensinamentos de Libras para ouvintes na Associação e pelo grupo "Projeto ASJA VERDE" criado na rede social "Facebook", onde este continha até o final do projeto 52 membros entre os participantes, outros surdos da Associação, amigos e simpatizantes ouvintes do projeto. Outro meio que foi utilizado para se comunicar entre os surdos foi o aplicativo "WhatsApp", onde a Diretoria da ASJA informava as datas dos encontros.

O projeto "ASJA VERDE" foi planejado e desenvolvido em 12 meses em conjunto com os técnicos do Instituto Pró-Terra e a Diretoria da ASJA e seus associados. Também contou com o apoio das Secretarias Municipais de Jahu de Meio Ambiente e da Cultura e Turismo. A equipe técnica foi formada por profissionais ouvintes da área ambiental do Instituto Pró-Terra, sendo que alguns sabiam Libras, e por alunos do curso de Libras da ASJA como intérpretes. Vale salientar que quando um ouvinte não entendia o sinal que 0 outro fazia ou não sabia se expressar em Libras, todos os participantes o ajudavam, além de contar com os alunos do curso nas interpretações durante as atividades para o responsável pelo registro das atas, sendo este um estagiário ouvinte que não conhecia a Libras. Eventualmente contou-se com a 
presença de intérpretes de Libras mais experientes mediando a interpretação para ouvintes que não compreendiam o conteúdo tratado.

Todas as datas dos encontros foram discutidas e escolhidas antecipadamente com os participantes, as quais sofreram alterações ao longo do projeto devido ao cronograma das atividades da ASJA.

$\mathrm{Na}$ primeira etapa o projeto foi escrito e apresentado a Diretoria de 2015 da Associação, a qual aprovou e cedeu o próprio espaço da sede para a realização do mesmo. O nome escolhido em português "ASJA VERDE" foi com intento de associar as atividades da ASJA e de seus integrantes ao contato com o meio ambiente interno e externo da associação. Este foi o momento também de criarem um nome em Libras e o logo para o projeto, facilitando sua referência na comunidade surda, conforme mostra a Figura 1. Tal nome em Libras criado por um dos membros da Diretoria da ASJA representa uma planta nascendo e se desenvolvendo, ganhando vida, assim como o próprio projeto.

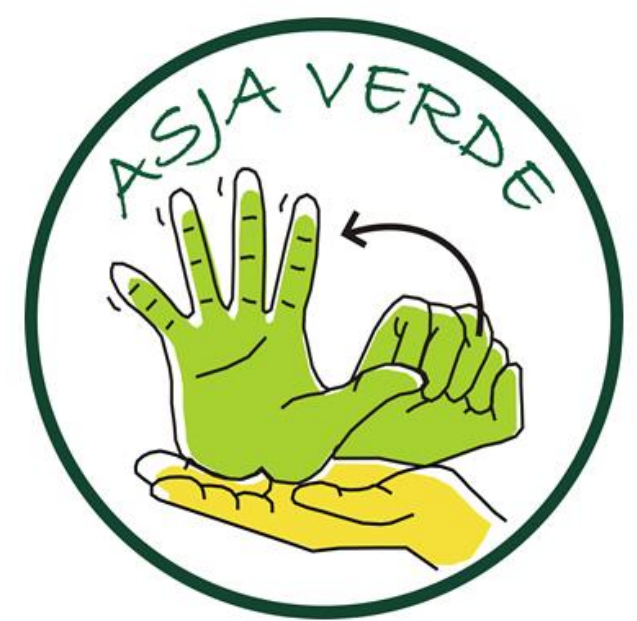

Figura 1: Logo e sinal do projeto ASJA VERDE.

Fonte: Própria autora.

$\mathrm{Na}$ segunda etapa, foram realizados dois encontros com alguns surdos associados e alunos do Curso de Libras da Associação que possuíam interesse em participar do projeto, mostrando como este seria desenvolvido ao longo do ano.

$\mathrm{Na}$ terceira etapa, foi realizado um encontro de diagnóstico da percepção ambiental dos participantes, onde estes fizeram Mapas mentais (OLIVEIRA, 2006) e a partir de sua avaliação pode-se planejar e realizar a quarta e última etapa, ocorrendo os 14 encontros em três Oficinas principais: Meio Ambiente, Cultura e de Sustentabilidade. Ao final do projeto, foi realizada uma confraternização com os participantes. 


\section{Resultados e discussões}

Ao todo, participaram do projeto ASJA VERDE 21 pessoas, sendo 14 associados, 04 integrantes da Diretoria da ASJA (totalizando 18 surdos) e 03 alunos ouvintes do Curso Básico e Intermediário de Libras, conforme ilustra o Quadro 1. Os participantes pertenciam aos municípios do Estado de São Paulo: Bauru, Barra Bonita, Dois Córregos, Jaú, São Carlos e São Paulo.

Quadro 1: Número de participantes do projeto ASJA VERDE.

\begin{tabular}{|c|c|c|c|}
\hline \multicolumn{2}{|r|}{ Participantes } & № de Pessoas & Porcentagem (\%) \\
\hline \multirow{2}{*}{ Surdos } & Associados & 14 & 67 \\
\hline & Diretoria & 4 & 19 \\
\hline \multirow{2}{*}{ Ouvintes } & Curso Básico de Libras & 1 & 5 \\
\hline & Curso Intermediário de Libras & 2 & 9 \\
\hline & TOTAL & 21 & 100 \\
\hline
\end{tabular}

Fonte: Própria autora.

Apesar de o projeto focar os surdos, a participação de alunos do curso de Libras da ASJA também foi importante, pois desta forma eles puderam entrar em contato com os membros da Associação e a compartilhar a Libras e a cultura, enriquecendo essa vivência e contribuindo para a sua formação e experiência na associação. Essa mescla de ouvintes e surdos permitiu com que a realização do projeto tivesse múltiplos olhares, ou seja, visões e ideias diferentes que unidas contribuíram para o desenvolvimento do mesmo.

Todos as observações e os diálogos foram anotados em um diário e após transformados em pequenos relatórios para análise do projeto.

\section{Oficinas}

As oficinas foram realizadas de abril a dezembro, totalizando 14 encontros, contabilizando mais de 70 horas. Como já foi dito, foram divididas em três temáticas principais: Meio Ambiente com quatro encontros, Cultura Surda com cinco encontros e de Sustentabilidade também com cinco encontros. Para poder atender alguns participantes que moravam em outros municípios e que trabalhavam durante a semana, os encontros foram realizados em maior parte nos finais de semana à tarde e no último mês nas sextas-feiras à noite. Cada encontro durou, em média, de duas a quatro horas.

A primeira oficina realizada foi a de Meio Ambiente, pois a partir desta pode-se fazer o diagnóstico da percepção ambiental para o planejamento das próximas atividades, por meio de Mapas mentais (OLIVEIRA, 2006). Após uma apresentação de slides e dos participantes localizarem a ASJA por meio do Google Maps, cada um recebeu um papel sulfite contendo o contorno da cidade de Jaú, onde deveriam desenhar dentro dela tudo aquilo que eles lembravam que Jaú possuía de meio ambiente e fora do mapa o que não tinha de meio ambiente no município. Os resultados dos mapas mentais mostraram seus conhecimentos prévios em relação ao ambiente em que estão inseridos, 
onde todos foram fiéis a realidade do município, principalmente pontuando os locais sociais e ambientais próximos a ASJA, como o Lago do Silvério, o Rio Jaú, a igreja, o Bosque Campos Prado e outros bairros. No lado rural, também se destacaram a monocultura da cana-de-açúcar, usinas e as cidades vizinhas. A Figura 2 ilustra um desses desenhos.

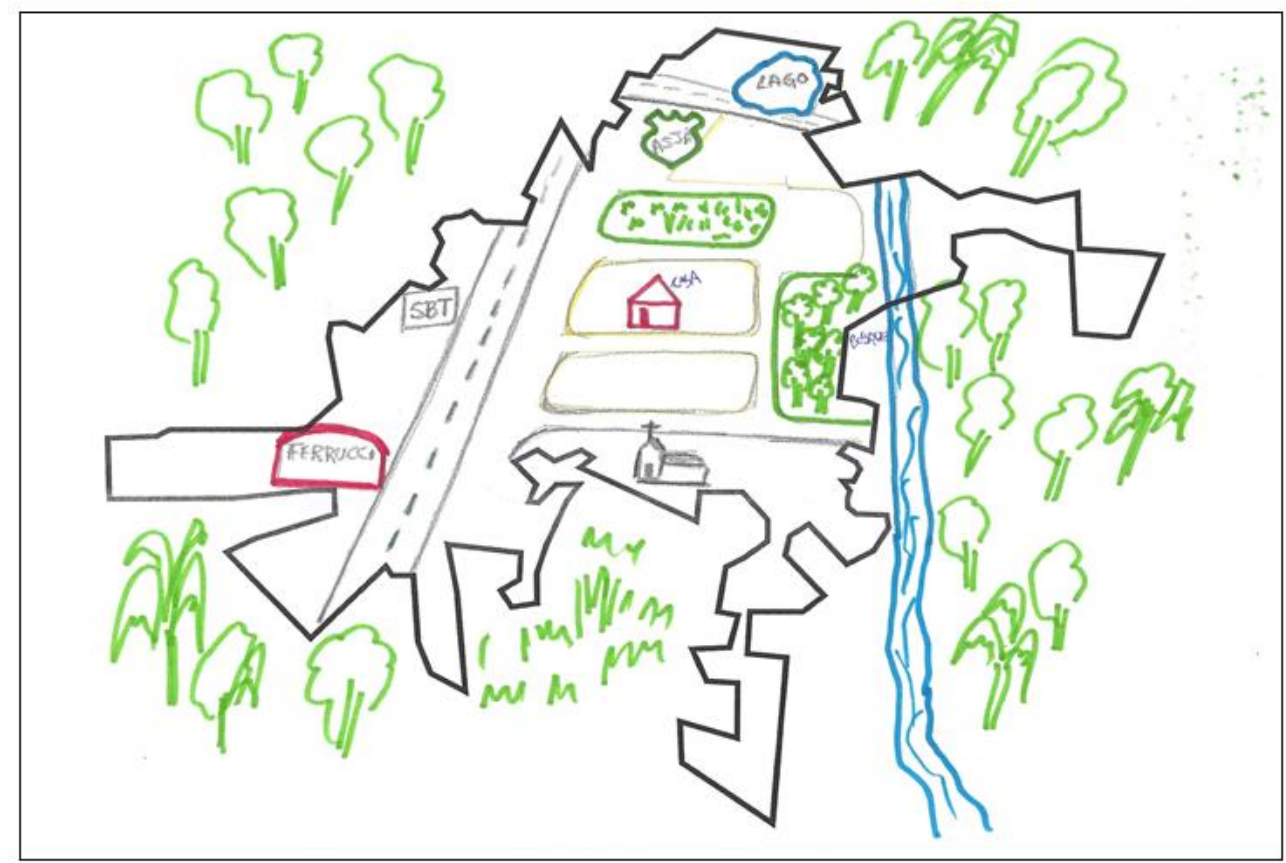

Figura 2: Mapa mental de um dos participantes surdos.

Também foi trabalhada nessa fase a sensibilização e conscientização socioambiental dos participantes, além debaterem tais questões e vivenciarem nas saídas de campo. Dessa forma, pode ser observada a evolução dessa percepção por meio das discussões e reflexões pelos participantes através das rodas de diálogos. Ao todo participaram 18 pessoas. O Quadro 2 resume as datas e os temas de tais encontros.

Quadro 2: Encontros das Oficinas de Meio Ambiente.

\begin{tabular}{|c|c|l|}
\hline Encontro & Data & \multicolumn{1}{c|}{ Temas } \\
\hline $\mathbf{1}^{\mathbf{0}}$ & 12/Abril & Diagnóstico de Percepção Ambiental e Introdução ao Meio Ambiente \\
\hline $\mathbf{2} \mathbf{0}$ & $23 /$ Maio & Flora \\
\hline $\mathbf{3}^{\mathbf{o}}$ & $28 /$ Junho & Visita ao Centro de Educação Ambiental Campos Prado \\
\hline $\mathbf{4}^{\mathbf{o}}$ & $31 /$ Outubro & Visita ao Instituto Pró-Terra e plantio de mudas \\
\hline
\end{tabular}

Fonte: Própria autora.

No primeiro encontro, buscou-se discutir sobre o conceito de meio ambiente e mostrar que o ser humano faz parte deste também, logo tudo o que ele produz - conhecimento, cultura, etc. - também faz parte do mesmo. Dessa forma, o meio ambiente não se restringe apenas a natureza, mas sim todas as atividades humanas, inclusives as atividades da ASJA e de cada um em suas casas e em sua cidade. Também foram discutidos os impactos negativos Revbea, São Paulo, V. 12, № 4: 219-239, 2017. 
ambientais, como a contaminação da água, dos solos e do ar, além de como funcionam os ecossistemas em equilíbrio.

No segundo encontro, abordou-se a temática das plantas, principalmente os benefícios das árvores, ilustrando por meio de sementes, folhas e flores coletadas próxima a Associação. Os participantes mais velhos reconheceram boa parte das sementes e compartilharam suas vivências de quando moravam em sítios. Ao final, todos aprenderam a fazer um terrário.

Apesar das saídas de campo terem tido menos presenças (em média 7 pessoas), estas foram as que mais os participantes gostaram, pois puderam sair da ASJA e conhecerem áreas verdes que nunca haviam sidos exploradas por eles no Município. Essas saídas de campo são fundamentais para o contato com o meio ambiente e a desenvolver a percepção ambiental pelo mesmo, além de permitir bons momentos antes, durante e depois das atividades. No terceiro encontro, o projeto contou com o apoio da Secretaria do Meio Ambiente de Jahu para utilizar o espaço do Centro de Educação Ambiental no Bosque Campos Prado, uma área verde aberta a alunos de escolas públicas e privadas que tenham interesse em fazer pequenas trilhas e participarem de projetos de Educação Ambiental da Prefeitura.

A visita ao bosque possibilitou o contato com trilhas, pois poucos participam dessas atividades devido a falta de intérpretes para os acompanharem. Os participantes conheceram árvores típicas do cerrado, da mata atlântica e de algumas espécies exóticas, aprendendo as diferenças desse conceito e das nativas regionais. Já a visita ao Pró-Terra eles puderam conhecer algumas atividades socioambientais da Instituição e depois puderam plantar mudas nativas no Parque do Rio Jaú, aprendendo técnicas de plantio e sobre o hidrogel.

A Figura 3 ilustra os melhores momentos destes encontros.

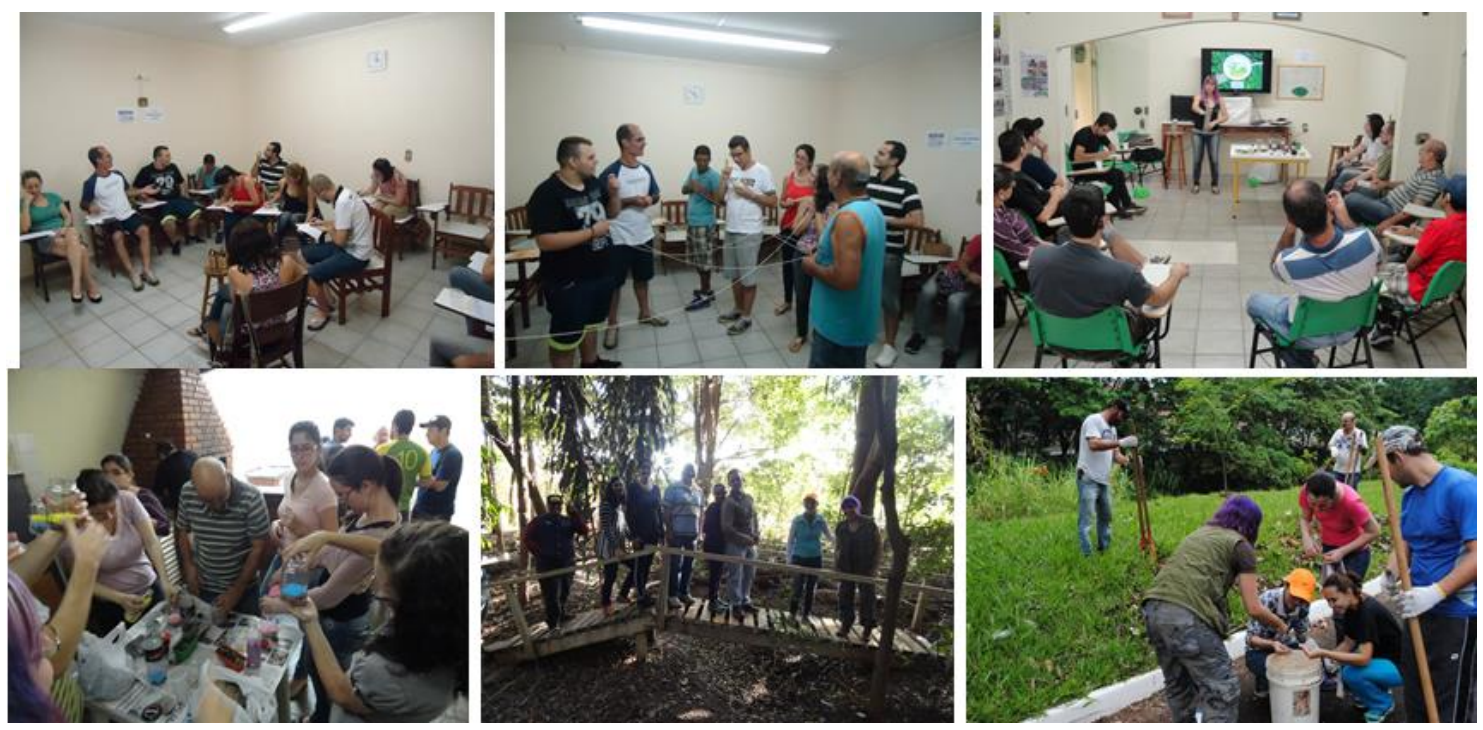

Figura 3: Oficina de Meio Ambiente.

Fotos: Próprios autores e Mariana Didone.

revista brasileira 
A segunda oficina realizada foi sobre a Cultura, onde os participantes puderam discutir mais sobre esta e como ela está atualmente na região, valorizando e resgatando os seus pertencimentos e o histórico de suas famílias. Vale frisar que desde 0 início do projeto trabalhou-se com os participantes a importância cultural e como ela faz parte do meio ambiente em que estão inseridos, assim como é destacada e valorizada em algumas correntes da Educação Ambiental, como a Biorregionalista e a Etnográfica (SAUVÉ, 2005) que valorizam.

Nesta fase, no primeiro encontro foram exploradas as diversas formas de se expressar a cultura, como desenhos e pinturas de artistas surdos, filmes e poemas em Libras. No segundo encontro, cada participante pode explorar o significado de seus nomes e de seus sinais, além de compartilhar suas histórias e de suas famílias, relembrando momentos alegres e desafios. Também ocorreu um passeio ao Museu Municipal de Jahu "José Raphael Toscano" no terceiro encontro, para que estes pudessem conhecer a história da cidade, desde a época em que habitavam os indígenas até os dias de hoje. No quinto encontro ocorreu o primeiro Cinema na ASJA, onde foi passado aos associados o filme indiano "Black" (2005), legendado, o qual contava a história de uma jovem garota que ficou surda e cega após uma doença logo nos primeiros meses de vida e com a ajuda de um professor conseguiu superar os obstáculos e, já adulta, formou-se. Tal história é inspirada na autobiografia de Helen Keller "A História de minha vida"3. A escolha foi para problematizar questões de independência e barreiras impostas pela sociedade.

Ao todo participaram 22 pessoas. O Quadro 3 detalha tais encontros e a Figura 4 resume os melhores momentos destes encontros.

Quadro 3 : Encontros das Oficinas de Cultura Surda.

\begin{tabular}{|c|c|l|}
\hline Encontro & Data & \multicolumn{1}{c|}{ Temas } \\
\hline $\mathbf{1}^{\mathbf{0}}$ & $19 /$ Julho & Introdução a Cultura \\
\hline $\mathbf{2}^{\mathbf{o}}$ & 08/Agosto & A História de cada um \\
\hline $\mathbf{3}^{\mathbf{0}}$ & 23/Agosto & Visita ao Museu Municipal de Jahu \\
\hline $\mathbf{4}^{\mathbf{0}}$ & 05/Setembro & I Exposição da História da Comunidade Surda de Jaú e Região \\
\hline $\mathbf{5}$ & 19/Setembro & Cinema na ASJA \\
\hline
\end{tabular}

Fonte: Própria autora.

${ }^{3}$ KELLER, H. A História de minha vida. José Olympio, 2008.

Tal livro escrito em 1902 inspirou o filme "O milagre de Anne Sullivan" (The Miracle Worker), filme norte americano de 1962 dirigido por Arthur Penn.

Revbea, São Paulo, V. 12, № 4: 219-239, 2017. 

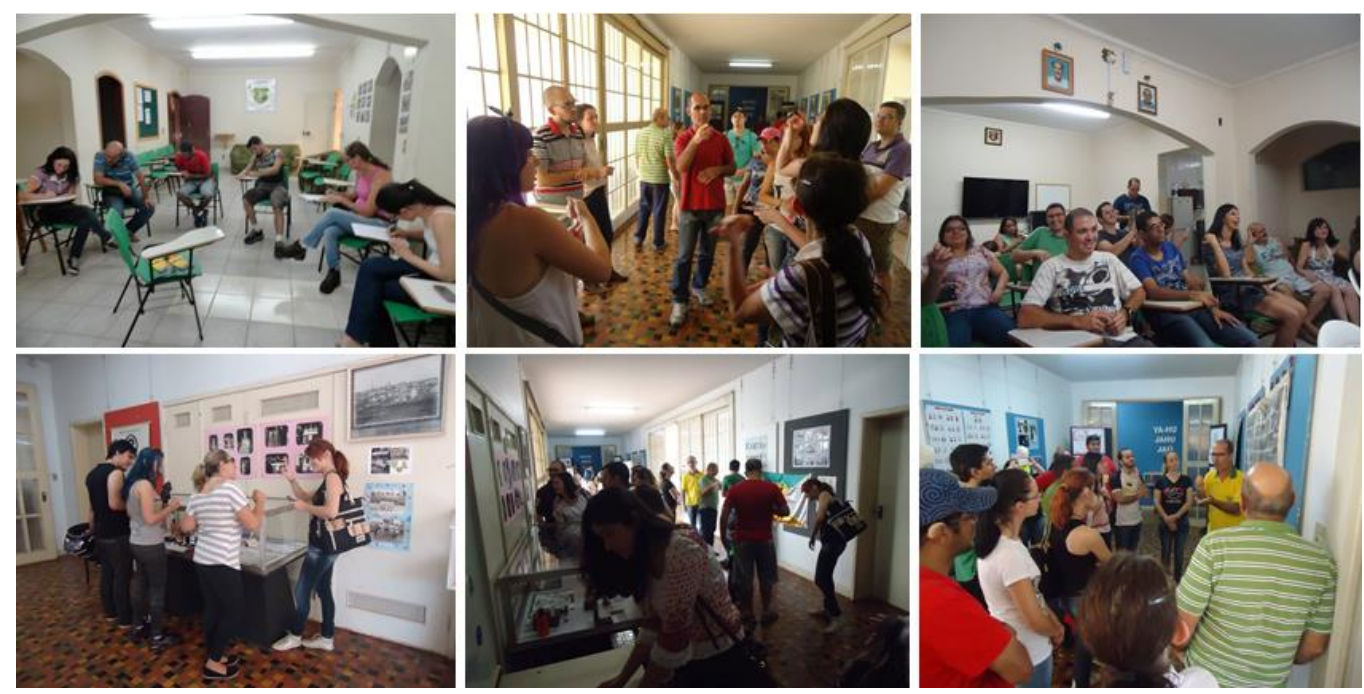

Figura 4: Oficina de Cultura Surda.

Fotos: Próprios autores.

Nesta etapa, no quarto encontro, também foi produzido e realizado a "I Exposição da História da Comunidade Surda de Jaú e Região" no Museu Municipal de Jahu. Para a sua concretização, contou com o apoio da Secretaria Municipal da Cultura e Turismo para utilizar o espaço do museu e ajudar na sua divulgação. Tal evento foi preparado uma semana antes de ficar exposto, o qual contou com o auxílio da Diretoria da ASJA e de alguns associados que contribuíram com seus acervos pessoais.

A exposição ficou no Museu do dia 5 a 31 de Setembro, em comemoração as atividades do "Setembro Azul", sendo que no dia 5, as $16 \mathrm{~h} 30$, ocorreu a inauguração, contando com a presença de 15 surdos, 06 ouvintes e outras pessoas que estavam passeando no momento da mesma.

Em resumo foram contados 80 anos de história dos surdos das cidades de Jaú, Rio Claro e de São Paulo, por meio de acervos pessoais dos associados e da própria ASJA como: fotos, aparelhos auditivos para surdos 45 anos de evolução dos Aparelhos de amplificação Sonora Individual (AASI) -, medalhas e troféus de competição, cadernos de fonoaudiologia, desenhos de artistas surdos da Associação, banners, uniformes de jogadores de futebol e do curso de Libras, uma bandeira com o logo antigo da ASJA, livros sobre Libras e a educação dos surdos, apostilas do curso de Libras, pôsters de sinais de time de futebol brasileiro, uma reportagem no jornal sobre os surdos, vídeos cassetes de histórias em Libras, uma raquete de tênis de mesa - usada pelo fundador da ASJA que também era surdo - , desenhos feitos durante o projeto ASJA VERDE, informativos explicando sobre a Libras, a Associação e o

\footnotetext{
4 A Comunidade Surda comemora o "Setembro Azul" devido ao Dia do Surdo na data 26 de setembro, onde são realizados diversas atividades e eventos em todas as cidades brasileiras. Também é lembrado neste mesmo mês o Congresso em Milão em 1880, onde tinha sido proibido o uso da língua de sinais na educação dos surdos de todo o mundo (SILVA, 2006). De acordo com a Diretoria da ASJA, a cor azul turquesa simboliza o orgulho em ser surdo, sendo que na Segunda Guerra Mundial as pessoas com deficiência eram identificadas com uma faixa azul fixada em seus braços e mortos nos campos nazistas.
}

revista brasileira educação ambiental 
Setembro Azul e uma linha do tempo contando a história dos surdos no Brasil e no mundo. A Figura 5 mostra os materiais que foram expostos durante a exposição.

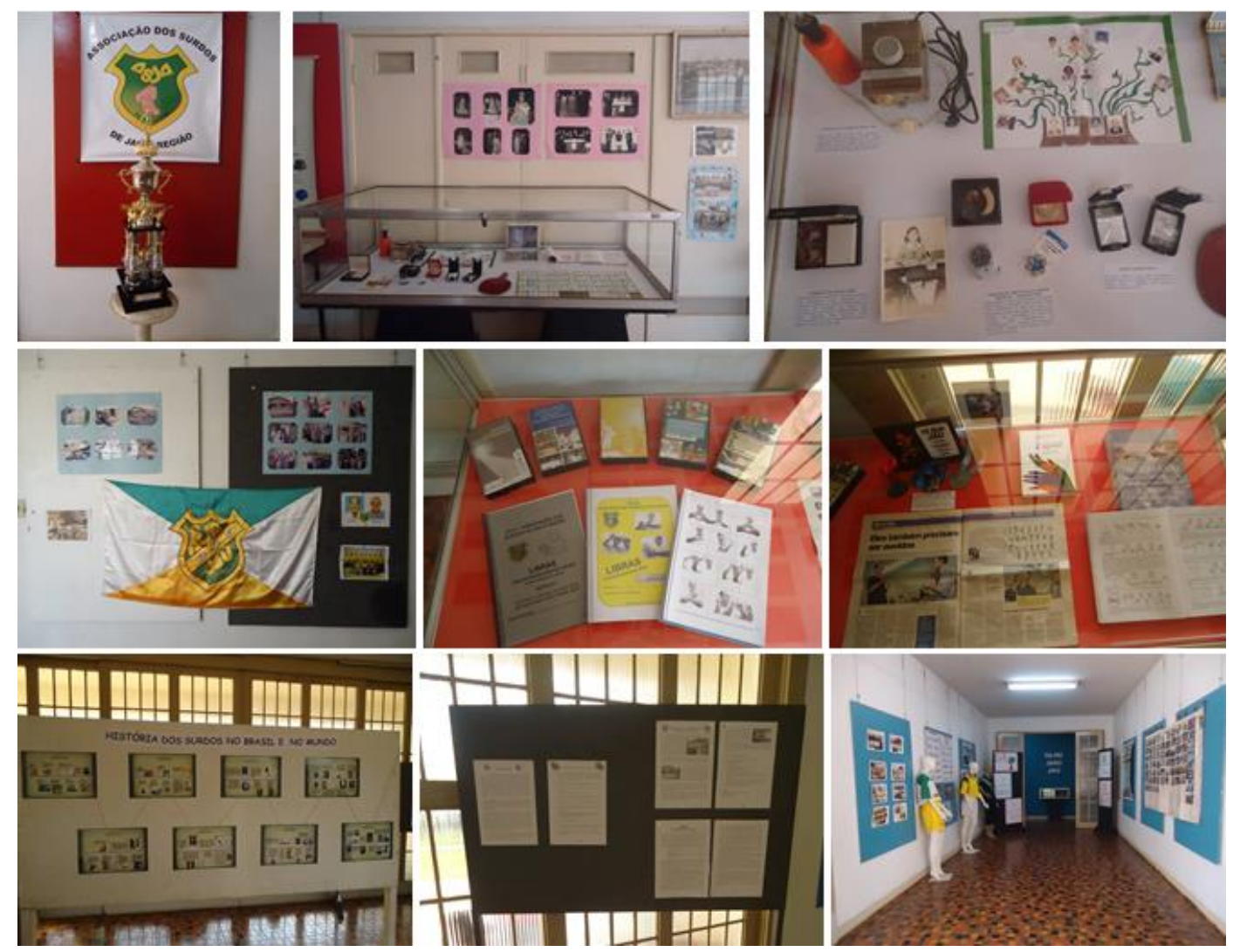

Figura 5: Materiais expostos no Museu.

Fotos: Própria autora.

A partir do livro de presença do próprio museu, pode-se calcular quantos visitantes este recebeu neste período, sendo que durante os 27 dias de exposição, 719 pessoas de diversos estados do Brasil viram a mostra. $O$ Quadro 4 (próxima página) mostra a origem de tais visitantes.

Além destes visitantes, também vieram 59 alunos de escolas públicas e particulares de Jaú do jardim de infância, 10 alunos de uma sala especial, 27 alunos do Ensino Fundamental I, 02 alunos do Fundamental II de uma escola estadual e 05 pessoas do Curso de Licenciatura em Ciências da USP - Pólo Jaú. Este último teve uma visita especial marcada no dia 12 de setembro orientada por membros da Associação, onde passaram uma tarde no Museu discutindo sobre as dificuldades da educação dos surdos nas escolas.

A partir desta Oficina, pode-se observar que muitos surdos já possuíam esse pertencimento e o orgulho de sua identidade, então a exposição auxiliou a expor suas histórias e conquistas a população geral, além de debaterem novamente sobre os seus direitos na sociedade ouvinte. $O$ pessoal de mais idade demonstrou mais interesse e cuidado ao montar essa amostra, elevando 
a autoestima de cada um e arrecadando materiais históricos para a nossa região. Isto possibilitou com que se identificassem como atores e atrizes da própria história de suas cidades. O Jornal Comércio do Jahu escreveu uma matéria neste período em comemoração também ao Setembro Azul, entrevistando a ASJA e alguns de seus membros (MONARI, 2015).

\begin{tabular}{|c|c|c|}
\hline Estados & Municípios & № de visitantes \\
\hline $\mathrm{AM}$ & Manaus & 6 \\
\hline GO & Goiatuba & 2 \\
\hline MS & Campo Grande & 3 \\
\hline \multirow{2}{*}{ MG } & Costa & 1 \\
\hline & Itapeva & 2 \\
\hline ES & São Mateus & 1 \\
\hline PR & Jacarezinho & 2 \\
\hline \multirow{22}{*}{ SP } & Araraquara & 2 \\
\hline & Bariri & 3 \\
\hline & Barra Bonita & 4 \\
\hline & Bauru & 6 \\
\hline & Birigui & 7 \\
\hline & Bocaina & 3 \\
\hline & Botucatu & 4 \\
\hline & Caraguatatuba & 1 \\
\hline & Dois Córregos & 7 \\
\hline & Dourado & 1 \\
\hline & Indaiatuba & 2 \\
\hline & Itapuí & 2 \\
\hline & Jaú & 371 \\
\hline & Maracai & 2 \\
\hline & Paraguaçu Paulista & 1 \\
\hline & Pederneiras & 6 \\
\hline & Ribeirão Preto & 1 \\
\hline & Rio Claro & 2 \\
\hline & São Carlos & 1 \\
\hline & São Manuel & 6 \\
\hline & São Paulo & 2 \\
\hline & Torrinha & 16 \\
\hline \multirow[t]{2}{*}{$\mathrm{SC}$} & Lages & 1 \\
\hline & TOTAL & 719 \\
\hline
\end{tabular}

Fonte: Própria autora.

A terceira e última Oficina realizada foi a de Sustentabilidade, onde os participantes discutiram o tripé da sustentabilidade da ASJA: meio ambiente, sociedade e economia. Dessa forma, cada dia foi trabalhado uma parte para poderem desenvolver o material no último encontro, discutindo assim o que seria a sustentabilidade; os aspectos ambientais como a água, os resíduos sólidos e o aquecimento global, seus impactos socioambientais; as atividades da ASJA e seu papel na sociedade, assim como as ações de organizações não governamentais e de instituições que atuam na cidade e a importância da parceria com essas os gastos e despesas da ASJA e formas de economia. 
Também foi realizado nesta etapa atividades que auxiliaram os participantes a explorarem suas habilidades e a criatividade para poderem lidar com possíveis problemas socioambientais dentro da própria Associação. Ao todo participaram 16 pessoas. O Quadro 5 resume as datas e os temas abordados de tais encontros.

\begin{tabular}{|c|c|l|}
\multicolumn{3}{|c|}{ Quadro 5: Encontros das Oficinas de Sustentabilidade. } \\
\hline Encontro & Data & \multicolumn{1}{c|}{ Temas } \\
\hline $\mathbf{1}^{\mathbf{0}}$ & $04 /$ Outubro & Introdução a Sustentabilidade \\
\hline $\mathbf{2} \mathbf{0}$ & $25 /$ Outubro & Sustentabilidade - Meio Ambiente \\
\hline $\mathbf{3}^{\text {o }}$ & $21 /$ Novembro & Sustentabilidade - Sociedade e Economia \\
\hline $\mathbf{4}^{\mathbf{o}}$ & $28 /$ Novembro & Criatividade e Habilidade \\
\hline $\mathbf{5} \mathbf{0}$ & $04 /$ Dezembro & Elaboração do "Plano de Sustentabilidade da ASJA" \\
\hline
\end{tabular}

Fonte: Própria autora.

Em relação às atividades que exploraram as aptidões dos participantes, pode-se observar grandes habilidades e criatividades destes em diversas áreas - artes, comunicação, gestão, exatas, etc. - e isso mostrou a potencialidade de atuação e desenvolvimento pessoal de cada um para a própria Associação. Para isso, seriam necessários atividades e cursos que estimulem os associados, como artesanato, informática, jardinagem, gastronomia, etc., para que se identifiquem com uma área e se dediquem nesta, podendo desenvolver trabalhos individuais e realizações pessoais. Entretanto, alguns dos participantes se fechavam nessas atividades ou salientavam que não sabiam fazer nada, indicando a possível necessidade de mais atividades que trabalhem com a autoconfiança destes dentro da própria ASJA.

Neste último encontro, os participantes foram divididos e três grupos, primeiramente, e propuseram práticas e atividades que melhorassem as questões ambientais dentro e fora da Associação, o bem-estar dos associados e visitantes, o compartilhamento de sua Cultura e a independência financeira da Associação. Ao final, os grupos foram reunidos e analisaram cada item, propondo também prazos para as suas realizações. Foi gerado o documento "Plano de Sustentabilidade da ASJA", contendo introdução, objetivos, metas e prazos das 44 ideias de ações e atividades que foram debatidas para serem realizadas na Associação, focando os seus aspectos ambientais - Educação Ambiental, recursos naturais, resíduos sólidos e infraestrutura -, sociais entretenimento, comunicação/divulgação e aprendizagem - e econômicos economias e gastos, planejamento e parcerias, serviços prestados e vendas. Tal documento foi apresentado, debatido e aprovado na Diretoria da ASJA em março de 2016, dando continuidade as ações do projeto ASJA VERDE nos seguintes anos.

A Figura 6 ilustra os momentos dessa última oficina. 

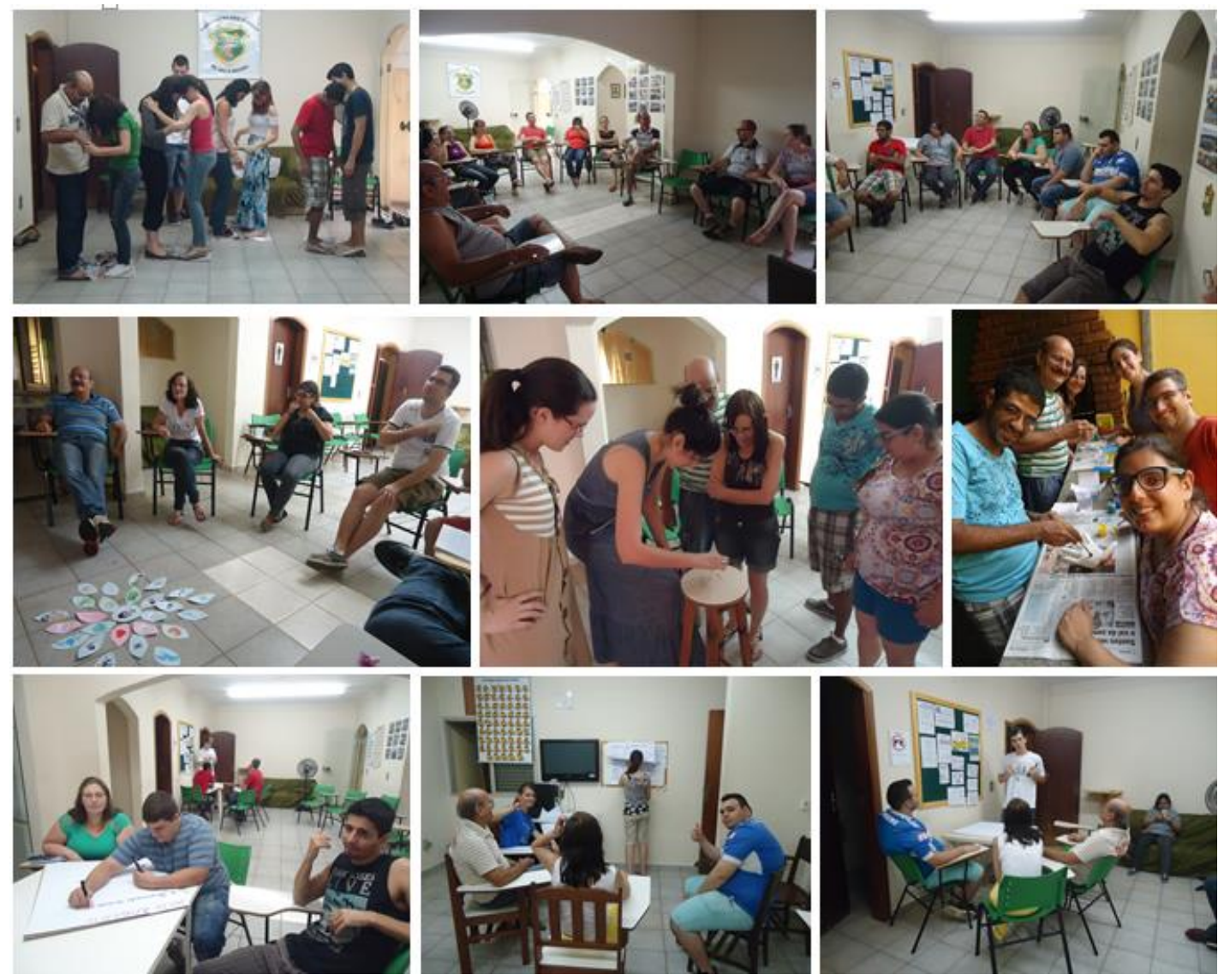

Figura 6: Oficinas de Sustentabilidade.

Fotos: Própria autora.

Durante a realização desta etapa, pode ser observado através das falas que alguns dos assuntos debatidos durante o projeto influenciou em algumas condutas dos participantes em suas casas e/ou trabalho, o que contribuiu também para a promoção da sustentabilidade individual.

Para simbolizar o encerramento da ASJA VERDE, foi realizada uma festa de confraternização em dezembro, onde compareceram 19 participantes. Neste dia também foram entregues os certificados aos participantes e uma lembrança do projeto. A Figura 7 mostra os momentos da confraternização.
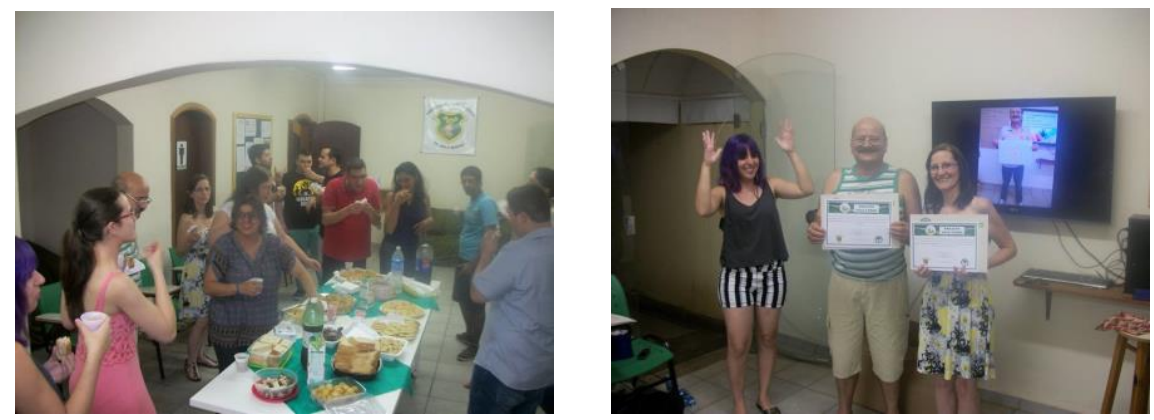

Figura 7: Confraternização do projeto ASJA VERDE.

Fotos: Diego Fernando do Nascimento.

Revbea, São Paulo, V. 12, № 4: 219-239, 2017. 
$\mathrm{Na}$ fase final, foram realizadas avaliações com a equipe técnica do projeto e recolhidos alguns depoimentos dos participantes sobre o mesmo, os quais destacamos a seguir três deles:

"Sobre o projeto ASJA VERDE, ele tem um papel fundamental e eu gosto muito dele, pois ele é importante e trouxe informação aos surdos. O trabalho oportunizou o acesso ao conhecimento aos surdos a fim de que pudéssemos contribuir para a nossa cidade. Desta forma os surdos também podem contribuir para um futuro melhor. Esse saber adquirido irá proporcionar uma vida mais sustentável'. Professor do Curso de Libras da ASJA, 42 anos, Jaú.

"Esta inciativa proporcionou aos surdos o conceito de preservação, fauna e flora. A primeira vez que conheci o projeto eu me encantei por ele porque havia informações que eu não conhecia e isso foi muito interessante e cada vez mais eu fui participando, pois não era só exposição e sim dinâmicas e diversões". Secretária da Diretoria da ASJA de 2015, 23 anos, Jaú.

"Aprendizado constante e prazeroso também. Aprender sobre meio ambiente é algo que eu nunca tinha visto e foi muito bom. Foi um ótimo aprendizado para sabermos os nomes e classificarmos as coisas. Eu gostei muito da ASJA VERDE e gostaria que continuasse". Associada, 53 anos, Barra Bonita.

\section{Sinais criados durante o projeto}

Durante o decorrer do projeto, foram discutidos diversos sinais para termos e conceitos ambientais. Pode ser observado que muitos não há um consenso, onde cada região do país pode utilizar um sinal específico para o mesmo objeto/conceito. Em determinados momentos, houve o consenso de todos os presentes para utilizar um dos sinais propostos durante a realização da ASJA VERDE. Entretanto, alguns sinais foram criados e combinados entre os participantes para serem utilizados durante a concretização do mesmo, totalizando três sinais como ilustram as Figuras 8, 9 e 10. 


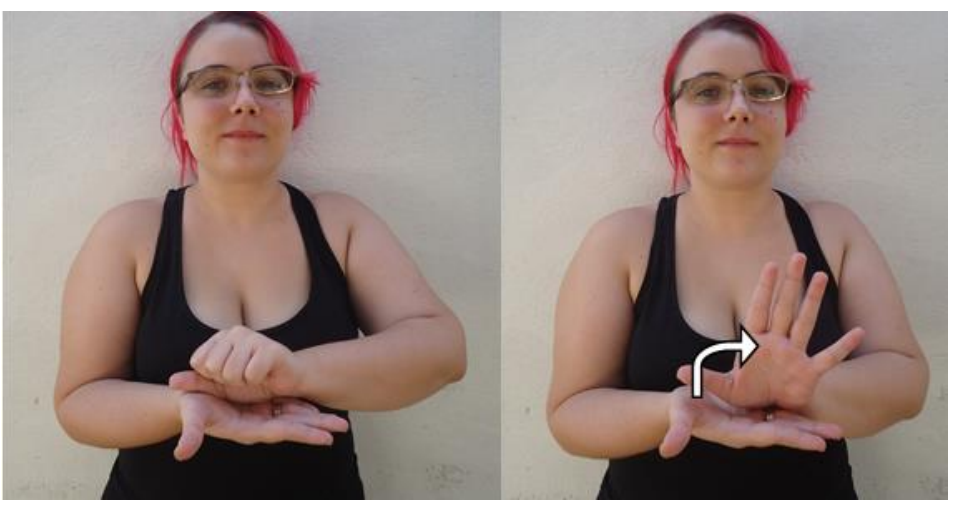

Figura 8: Sinal criado para o projeto "ASJA VERDE". Representa como uma planta nascendo e mantendo-se viva, assim como o projeto.

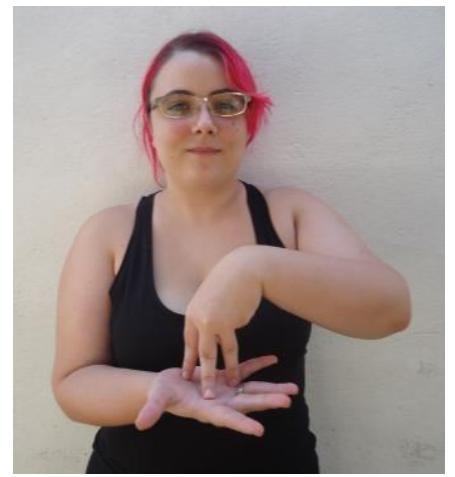

Figura 9: Sinal criado para o termo "Sustentabilidade", o qual significa o tripé: meio ambiente, sociedade e economia.
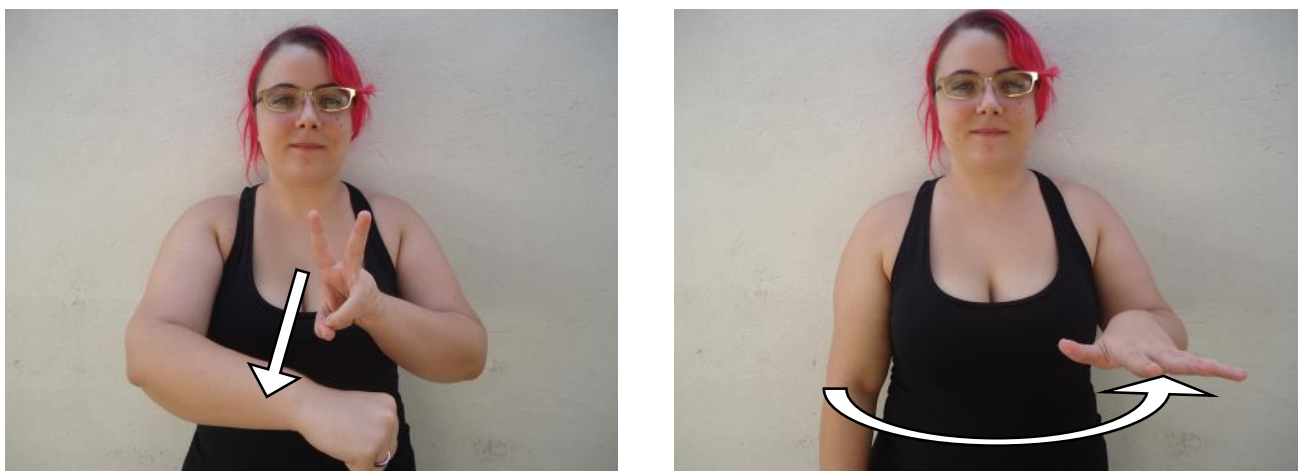

Figura 10: Sinal escolhido para o termo "Meio Ambiente" no primeiro encontro das Oficinas de Meio Ambiente. Foram escolhidos os sinais "cuidar/zelar" e "ambiente" devido à preocupação dos participantes em conservar o seu redor.

\section{Conclusões}

O projeto ASJA VERDE possibilitou o desenvolvimento de práticas de Educação Ambiental com a comunidade surda. As técnicas utilizadas durante o projeto como dinâmicas e brincadeiras permitiram com que os participantes se descontraíssem e criassem um clima, às vezes, de trabalho em equipe e outras vezes de competição, todas de forma positiva. As atividades lúdicas como desenho e pintura possibilitaram o contato mais íntimo de cada indivíduo, onde pode-se buscar o seu autoconhecimento para explorá-lo e apresentá-lo aos demais, fazendo com que cada um aprendesse mais sobre o outro.

Os participantes surdos puderam refletir e opinar sobre as questões socioambientais da sua comunidade através das rodas de diálogos e do retorno dos participantes nas conversas, assumindo-se como um sujeito que permite fazer as mudanças na sociedade, capacitando-o e valorizando-o a se manifestar e a participar também da comunidade ouvinte, lutando por seus direitos e deveres. O interessante neste projeto foi que tanto jovens quanto adultos puderam trabalhar em equipe, valorizando as experiências dos mais 
velhos e a animação dos mais jovens, estimulando a percepção ambiental de todos. Desta forma, fortaleceu o sentimento de pertencimento para participarem mais ativamente na Associação, trazendo futuramente melhorias concretas e constantes. Este projeto também auxiliou no crescimento individual de cada participante, estimulando a sua criatividade, habilidades e a sua autoestima, mostrando o quão eles são importantes tanto individualmente quanto coletivamente para a Associação. O interesse na gestão da Associação fez com que alguns participantes se tornassem parte da Diretoria de 2016.

A Oficina de Meio Ambiente possibilitou a sensibilização dos surdos, convidando-os a interagirem mais com a natureza e a contemplá-la, além terem ideias para o melhoramento da qualidade ambiental da Associação. A Oficina Cultural permitiu com que os mais velhos promovessem o orgulho de ser surdo, da sua língua e da história de sua comunidade, auxiliando na reflexão dos jovens sobre a educação de hoje e do futuro dos surdos. A exposição no Museu permitiu um começo para esse levantamento, sendo necessário agora aprofundá-lo mais e dar continuidade as celebrações da história e da cultura para que não sejam esquecidas ou perdidas. A Oficina de Sustentabilidade contribuiu para que os participantes se preocupassem mais com a Associação e seus associados (principalmente com o futuro destes). Também incentivou o interesse em trazerem mais atividades e cursos para os próprios surdos, para que estes se qualifiquem e se profissionalizem.

Em resumo, o Projeto ASJA VERDE foi tão bem acolhido e desenvolvido que a ASJA resolveu dar continuidade em 2016, focando agora na concretização do "Plano de Sustentabilidade" que os participantes elaboraram em 2015. Outros próximos passos seriam trabalhar mais os conceitos de meio ambiente que não há sinais convencionados, além de discutir mais os sinais em si já que é um tema que não foi abordado na época de escola na maioria dos adultos presentes. Os momentos vivenciais que os participantes tiveram no projeto servirão para também as próximas etapas, explorando mais os elementos práticos no dia a dia e os assuntos mais complexos, aprofundando mais nos diálogos e na realização das ações da ASJA VERDE dentro da Associação.

\section{Referências}

ALBRES, N. A. A construção dos sinais e sua mobilidade específica. In: LACERDA, C. B. F. de; SANTOS, L. F. dos (Org.). Tenho um aluno surdo, e agora? Introdução à Libras e educação de surdos. São Carlos: EDUFSCAR, 2013. p. 81-98.

ASJA - Associação dos Surdos de Jaú e Região. Projeto ASJA VERDE. Disponível em: <http://www.asja.com.br/\#!asja-verde/c1xsm>. Acesso em: 20 jul. 2015.

BLACK. Direção: Sanjay Leela Bhansali, Produção: Sanjay Leela Bhansali, Anshuman Swami, Aman Gill, Gautami Bhatt e Kuldeep Rathore. India: 
Applause Entertainment Ltd., Applause Bhansali Productions e SLB Films Pvt. Ltd, 2005, 1 DVD (122 min).

BORGES, J. A. de S. Educação ambiental na perspectiva da educação inclusiva. Olhar de Professor, Departamento de Métodos e Técnicas de Ensino Brasil, v. 14, n. 2, p. 285-292, 2011. Disponível em: $<$ http://www.revistas2.uepg.br/index.php/olhardeprofessor>. Acesso em: 10 jul. 2014.

BRASIL. Lei no 9.795 de 27 de abril de 1999. Dispõe sobre a educação ambiental, institui a Política Nacional de Educação Ambiental e dá outras providências. In: SARAIVA. Legislação de Direito Ambiental. São Paulo: Saraiva, 2008. ISBN 97885-02-06834-6. (Coleção Saraiva de Legislação).

BRASIL. Coletânea de Legislação Ambiental, Constituição Federal (1988). Odete Medauar (Org.). 10. ed. São Paulo: Editora Revista dos Tribunais, 2011.

BRASIL. Lei no 10.436, de 24 de abril de 2002. Dispõe sobre a Língua Brasileira de Sinais - Libras e dá outras providências. Disponível em: $<$ http://www.planalto.gov.br/ccivil 03/leis/2002/110436.htm>. Acesso em: 10 set. 2014.

CAMPELLO, A. R. e S. Pedagogia Visual: sinal na educação dos surdos. In: PERLIN, Gladis; QUADROS, R. M. de (Org.). Estudos Surdos II. Petrópolis: Arara Azul, 2007. p. 100-131.

CBS - CONFEDERAÇÃO BRASILEIRA DOS SURDOS. Associações e entidades de surdos no Brasil. Disponível em: <http://www.cbsurdos.org.br/associacoes.htm>. Acesso em: 10 jul. 2015.

FORTE, A. P. S. O.; SILVA, A. M. T. B. da. Educación inclusiva - Ampliando horizontes na educação dos surdos: propostas de atividades pedagógicas. In: Congresso lberamericano de Educación, 2010, Buenos Aires. Anais. Buenos Aires, 2010. p. 24.

FUNDAÇÃO PREFEITO FARIA LIMA - CEPAM; Unidade de Políticas Públicas - UPP. Pensando a gestão partilhada: a agenda 21 local. São Paulo, 2001.

HÖHER, P. B.; PERES, P. E. C. Percepções de alunos surdos em trilha ecológica com o uso dos diferentes sentidos: uma abordagem da educação ambiental. Monografias Ambientais, REMOA/UFSM, v. 6, n. 6, p. 1341-1353, mar/2012.

IBGE. Censo demográfico 2010: características gerais da população, religião e pessoas com deficiência. Rio de Janeiro, 2010. p. 215. Disponível em: $<$ http://biblioteca.ibge.gov.br/visualizacao/periodicos/94/cd 2010 religiao defici encia .pdf>. Acesso em: 10 jul. 2014.

INES. Institucional. Disponível em: $<$ http://www.ines.gov.br/ines portal novo/\#none>. Acesso em: 10 jul. 2014. 
INSTITUTO PRÓ-TERRA. Notícias. Disponível em: $<$ http://www.institutoproterra.org.br/pag noticia.php?id=203>. Acesso em: 10 jul. 2015.

LODI, A. C. B. Ensino da língua portuguesa como segunda língua para surdos: impacto na Educação Básica. In: LACERDA, C. B. F. de; SANTOS, L. F. dos (Org.). Tenho um aluno surdo, e agora? Introdução à Libras e educação de surdos. São Carlos: EDUFSCAR, 2013. p. 165-184

MARTINO, M. M. Ensaio sobre a surdez: perspectivas históricas. 2011. 64f. Monografia (Licenciatura em Pedagogia) - Faculdade de Educação, Universidade de Brasília, Brasília - DF. 2011.

MASSUTTI, M.; QUADROS, R. M. de. CODAs brasileiros: LIBRAS e Português em zonas de contato. In: PERLIN, G.; QUADROS, R. M. de (Org.). Estudos Surdos II. Petrópolis: Arara Azul, 2007. p. 238-266.

MIORANDO, T. M. Formação de profissionais: mais professores para a escola sonhada. In: QUADROS, Ronice Müller de (Org.). Estudos Surdos I. Petrópolis: Arara Azul, 2006. p. 76-109.

MONARI, A. C. Dia Nacional do Surdo marca luta por espaço na sociedade. Jornal Comércio do Jahu, Jaú, 26 de setembro 2015. Disponível em <http://www.comerciodojahu.com.br/noticia/1335652/dia-nacional-do-surdomarca-luta-por-espaco-na-sociedade>. Acesso em: 27 set. 2015.

OLIVEIRA, N. A. da S. A Educação Ambiental e a percepção fenomenológica, através de mapas mentais. Revista Eletrônica do Mestrado em Educação Ambiental, ISSN 1517-1256, v. 16, p. 32-46, jan./jun. 2006. Disponível em: $<$ https://www.seer.furg.br/remea/article/view/2779>. Acesso em: 5 mai. 2014.

PALMA, I. R. Análise da Percepção Ambiental como instrumento ao planejamento da educação ambiental. 2005. 83 f. Dissertação (Mestrado em Engenharia), Universidade Federal do Rio Grande do Sul - UFRGS: Porto Alegre, 2005.

PELICIONI, M. C. F.; PHILIPPI JUNIOR, A. Educação Ambiental: Desenvolvimento de Cursos e Projetos. 2ª ed. São Paulo: Signus, 2002.

PEREIRA, C. A. R. Educação Ambiental para surdos na educação básica. Revista Eletrônica do Mestrado em Educação Ambiental, E-ISSN 15171256, v. 30, n. 2, p. 6-26, jul./dez. 2013. Disponível em: $<$ https://www.seer.furg.br/remea/article/view/3753>. Acesso em: 5 mai. 2014.

PINTO, P. L. F.; REZENDE JÚNIOR, F. F. Os surdos nos rastros da sua intelectualidade específica. In: PERLIN, G.; QUADROS, R. M. de (Org.). Estudos Surdos II. Petrópolis: Arara Azul, 2007. p. 190-211.

SÁ, M. L. Pertencimento. In: FERRARO JÚNIOR. L. A (Coord.). Encontros e Caminhos: Formação de Educadores Ambientais. Brasília: MMA, Diretoria de Educação Ambiental, 2005; v. I., p. 245-256. 
SAUVE, L. Uma cartografia das correntes em Educação Ambiental. In: SATO, M.; CARVALHO, I. C. M. (Orgs.). Educação Ambiental: pesquisas e desafios. Porto Alegre: Artmed, 2005. Disponível em: $<$ http://web.unifoa.edu.br/portal ensino/mestrado/mecsma/arquivos/sauvel.pdf >. Acesso em: 27 jan. 2015.

SILVA, Vilmar. Educação de surdos: uma releitura da primeira escola Pública para surdos em Paris e do Congresso de Milão em 1880. In: QUADROS, Ronice Müller de (Org.). Estudos Surdos I. Petrópolis: Arara Azul, 2006. p. 1437.

SORRENTINO, M.; TRAJBER, R.; MENDONÇA, P.; FERRARO Jr., L. A. Educação ambiental como política pública. Educação e Pesquisa, São Paulo, v. 31, n. 2, p. 285-299, maio/ago, 2005.

STOKOE, W. C. Sign language structure. Silver Spring: Linstok Press. [1960] 1978.

STRÖBEL, Karin Lilian. História dos surdos: representações "mascaradas" das identidades surdas. In: PERLIN, Gladis; QUADROS, Ronice Müller de (Org.). Estudos Surdos II. Petrópolis: Arara Azul, 2007. p. 18-37.

STUMPF, M. R. Mudanças Estruturais para uma Inclusão Ética. In: QUADROS, R. M. de (Org). Estudos Surdos III. Petrópolis: Arara Azul, 2008. p. 14-29.

TEIXEIRA, T. Intervenção Participativa de Educação Ambiental na ASJA Associação dos Surdos de Jaú e Região. 2015. 47 f. Monografia (Especialização de Educação Ambiental para a Sustentabilidade), Centro Universitário Senac: Campus Santo Amaro, São Paulo, 2015.

THIOLLENT, M. Metodologia da pesquisa-ação. São Paulo: Cortez, 2003. 